\title{
Pathogenesis of high-altitude pulmonary oedema
}

To the Editor:

We have read with great interest the paper by WEST et al. [1], regarding the stress failure mechanism of pulmonary capillaries in the pathogenesis of high-altitude pulmonary oedema (HAPE), and would like to add some considerations. HACKETT et al. [2] described a high incidence of HAPE in subjects without the right pulmonary artery. Recently, we have reported a case of unilateral, left sided HAPE in a subject with a right pulmonary artery hypoplasia [3], that also underlines the importance of a restricted pulmonary vascular bed in the development of HAPE. Other reports of HAPE have been described in association with a congenital $[4,5]$ or acquired [6] pulmonary artery occlusion. In these subjects, HAPE usually occurs at moderate altitude and is sometimes recurrent $[5,6]$. All these observations confirm the HAPE susceptibility in subjects with pulmonary artery abnormalities and are consistent with the pathogenetic mechanism proposed by West and Mathieu-Costello [7].

In people without anatomical defects of the pulmonary vasculature the most likely hypothesis is that proposed by HULTGREN [8]: an uneven pulmonary vasoconstriction, that leads to high pressure in the non-vasoconstricted pulmonary vessels. This hypothesis is supported by the radiological appearance of a patchy pulmonary oedema and by the increased and uneven pulmonary perfusion in HAPE susceptible subjects after hypoxic breathing [9]. Although not yet proven in humans, stress failure of pulmonary capillaries appears to be the best model to explain the pathogenesis of HAPE.

\section{References}

1. West JB, Colice GL, Lee Y-J, et al. Pathogenesis of high-altitude pulmonary oedema: direct evidence of stress failure of pulmonary capillaries. Eur Respir J 1995; 8: 523-529.

2. Hackett PH, Creagh CE, Grover RF, et al. High-altitude pulmonary edema in persons without the right pulmonary artery. N Engl J Med 1980; 320: 1070-1073.

3. Fiorenzano G, Rastelli V, Greco V, Di Stefano A, Dottorini M. Unilateral high-altitude pulmonary edema in a subject with right pulmonary artery hypoplasia. Respiration 1994; 61: 51-54.

4. Rios B, Driscoll DJ, McNamara DG. High-altitude pulmonary edema with absent right pulmonary artery. Pediatrics 1985; 75: 314-317.

5. Levine SJ, White DA, Fels AOS. An abnormal chest radiograph in a patient with recurring high altitude pulmonary edema. Chest 1988; 94: 627-628.

6. Torrington KG. Recurrent high-altitude illness associated with right pulmonary artery occlusion from granulomatous mediastinitis. Chest 1989; 96: 1422-1423.

7. West JB, Mathieu-Costello O. High altitude pulmonary edema is caused by stress failure of pulmonary capillaries. Int J Sports Med 1992; 13: S54-S58.

8. Hultgren HN. High altitude pulmonary edema. In: Hegnauer AH, ed. Biomedieine of High Terrestrial Elevations. New York, Springer-Verlag, 1969; pp. 131-141.

9. Viswanathan R, Subramanian S, Radha TG. Effect of hypoxia on regional lung perfusion, by scanning. Respiration 1979; 37: 142-147.

G. Fiorenzano*, M. Dottorini**.

*Pulmonary Unit, "E. Morelli" Hospital, Via Zubiani, 33-23039 Sondalo, Italy. **Pulmonary Unit, "R. Silvestrini" Hospital, Perugia, Italy. 